\title{
Serum IGF-I, IGFBP-3, and matrix metalloproteinase-7 levels and acquired chemo-resistance in advanced colorectal cancer
}

\author{
Rosa Gallego ${ }^{1}$, Jordi Codony-Servat ${ }^{2}$, Xabier García-Albéniz' ${ }^{1}$ \\ Enric Carcereny', Raquel Longarón ${ }^{2}$, Angeles Oliveras ${ }^{1}$, Mónica Tosca ${ }^{1}$, \\ Josep Maria Augé ${ }^{3}$, Pedro Gascón ${ }^{1}$ and Joan Maurel ${ }^{1}$
}

Departments of ${ }^{1}$ Medical Oncology, ${ }^{2}$ Biology and ${ }^{3}$ Biochemical, Hospital Clínic Barcelona, Institut d'Investigacions Biomèdiques August Pi i Sunyer (IDIBAPS), Centro de Investigación Biomédica en Red de Enfermedades Hepáticas y Digestivas (CIBERehd), University of Barcelona, Catalonia, Spain

(Correspondence should be addressed to J Maurel, Medical Oncology Department, Hospital Clínic Barcelona, Villarroel 170, 08036 Barcelona, Spain; Email: jmaurel@ clinic.ub.es)

\begin{abstract}
Insulin-like growth factor-I (IGF-I) is thought to have antiapoptotic and mitogenic properties in colorectal cancer, whereas IGF-binding protein-3 (IGFBP-3) seems to exert a pro-apoptotic effect. Additionally, matrix metalloproteinase-7 (MMP-7), an enzyme with in vitro ability to degrade IGFBP-3, has been shown to be a prognostic factor in advanced colorectal cancer (ACRC). We studied whether chemotherapy treatment for ACRC modulates IGF-I, IGFBP-3, and MMP-7 serum levels. In 41 patients undergoing first-line therapy for ACRC, serum levels of IGF-I, IGFBP-3, and MMP-7 were measured with immunoassays at baseline and every 3 months until progressive disease, or a maximum of five determinations, during a chemotherapy regimen of either FOLFOX or FOLFIRI therapies. Associations were assessed for paired samples, using $t$-test or Wilcoxon ranks test depending on normality of the variable, verified with Shapiro-Wilk test. An average of four extractions (range 3-5) were done, for a total of 157 determinations. Mean pretreatment values of IGF-I, IGFBP-3, and MMP-7 were $83(95 \% \mathrm{Cl}, 73-92) \mathrm{ng} / \mathrm{ml}, 2372(95 \% \mathrm{Cl}, 2121-2623) \mathrm{ng} / \mathrm{ml}$, and $10.6(95 \% \mathrm{Cl}, 7.21-13.98) \mathrm{ng} / \mathrm{ml}$ respectively. No significant changes in IGF-I were found, but a significant increase in IGFBP-3 serum concentrations was observed during or after chemotherapy treatment without progressive disease, compared with basal levels $(P<0.001)$. A significant decrease in IGFBP-3 to $1983 \mathrm{ng} / \mathrm{ml}(95 \% \mathrm{Cl}, 1675-2292)$ and a significant increase in MMP-7 levels to $14.6(7.6-21.7) \mathrm{ng} / \mathrm{ml}$ were observed at progression of disease compared with baseline and treatment levels $(P<0.001)$. This study shows that IGFBP-3 and MMP-7 serum levels change during chemotherapy treatment. The increased MMP-7 levels at disease progression support the hypothesis that this protease could play a role in acquired resistance by degrading IGFBP-3.
\end{abstract}

Endocrine-Related Cancer (2009) 16 311-317

\section{Introduction}

The insulin-like growth factor (IGF) system is composed of two peptide ligands (IGF-I and IGF-II) that are mitogenic in normal and neoplastic cells, two cell surface tyrosine kinase receptors (IGF-IR and IGF-IIR), and a family of six IGF-binding proteins (IGFBPs 1-6). IGF-IR is activated by binding either to IGF-I or to IGF-II, binding the former with higher affinity than the latter. IGF-I and IGF-II act as growth factors by autocrine, paracrine, and endocrine mechanisms (Jones \& Clemmons 1995, Davies et al. 2006).

Most circulating IGFs are produced in the liver and are subject to complex regulation by the $\mathrm{GH}$ and nutritional factors. IGFBPs modulate IGF-I and IGF-II bioavailability in both circulation and cellular microenvironment. IGFBP-3 binds to more than $95 \%$ of the IGF-I in serum and influences cell proliferation by 
modulating the access of IGFs to the IGF-IR (Pommier et al. 1993, Michell et al. 1997, Pollak et al. 2004, Davies et al. 2006).

IGFBP-3 acts as a regulator in the dividing and differentiation processes at the intestinal crypt. Normal colonic epithelium shows IGFBP-3 staining, especially of the cells in the top half of the crypt. On the contrary, undifferentiated colorectal cancer shows weak staining for IGFBP-3 (Williams et al. 2000). In fact, it seems that only the stromal component of the tumors, but not the malignant epithelial cells, expresses IGFBP-3 as a feedback mechanism of IGF-IR regulation (Jenkins et al. 2005). This could be related either to an aberrant promoter methylation of IGFBP-3 (Tomii et al. 2007) or to the mutational status of p53 (Buckbinder et al. 1995).

Metalloproteinases (MMPs) are a family of proteolytic enzymes that participate in the degradation of different components of the extracellular matrix $(\mathrm{ECM})$ and in regulating the tumor microenvironment. MMP-7 (matrilysin) is the smallest of the more than 20 members of the group. While other MMPs are produced in the stroma, MMP-7 is synthesized in tumor cells of epithelial and glandular epithelial origin; it participates directly in the process of invasion and metastases in colorectal cancer (Zeng et al. 2002, Curran et al. 2004, Kurokawa et al. 2005). MMP-7 serum levels have also been associated with poor prognosis in metastatic colorectal cancer (Maurel et al. 2007).

Recent data have shown that MMP-7 possesses panIGFBP protease activity (Nakamura et al. 2005). MMP-7 proteolysis of IGFBP-3 plays a crucial role in regulating IGF-I bioavailability and thus promotes cell survival (Miyamoto et al. 2004). MMP-7 also participates in epithelial-mesenchimal signaling. MMP-7 cleavage of IGFBP-5 releases IGF-II that plays a role as an autocrine myofibroblast growth factor (Hemers et al. 2005).

In this study, we examined whether chemotherapy treatment in advanced colorectal cancer (ACRC) modulates IGF-I, IGFBP-3, and MMP-7 serum levels. In addition, we examined the relationship between IGF-I, IGFBP-3, and MMP-7 levels before treatment and at disease progression.

\section{Methods}

\section{Study population}

Patients were recruited from the metropolitan area served by our hospital in Barcelona. Between September 2001 and December 2004, a total of 120 chemonaive patients with ACRC undergoing first-line chemotherapy were consecutively enrolled for biological studies. Out of the 120 recruited patients, 41 individuals with a minimum of three serial determinations were selected for the study. CT scans were done every 3 months until disease progression. Data were collected prospectively. Written informed consent was obtained from every patient and the local Ethics Committee approved the study.

\section{Measurements of IGF-I, IGFBP-3, and MMP-7}

Serum samples were stored at $-80{ }^{\circ} \mathrm{C}$ until analyzed. IGF-I, IGFBP-3, and MMP-7 levels were measured with immunoassays at baseline and then every 3 months until disease progression, or a maximum of five determinations, during a chemotherapy regimen of either FOLFOX or FOLFIRI therapies. MMP-7 (Quantikine, USA) was determined using a quantitative solid-phase sandwich enzyme-linked immunosorbent assay (ELISA) and tested in duplicate. MMP-7 technique can detect both pro- and active forms of recombinant human MMP-7.

\section{Statistical analysis}

The study was designed as a prospective observational exploratory study. Recorded variables were age, sex, date of birth, date of disease progression, death or last follow-up, performance status (Eastern Cooperative Oncology Group), number and site of metastasis, and serum levels of carcinoembrionary antigen (CEA), lactate dehydrogenase (LDH), alkaline phosphatase (ALP), IGF-I, IGFBP-3, and MMP-7 as described above. Continuous variables are described as mean (95\% CI) or median (range) depending on the fulfillment of normality criteria. Associations for paired samples were assessed using $t$-test or Wilcoxon ranks test depending on the normality of the variable, verified with the Shapiro-Wilk test.

\section{Results}

IGF-I and IGFBP-3 were measured in serum samples of 41 patients receiving FOLFOX or FOLFIRI as first-line therapy for ACRC. Median age was 68 (range $38-81)$ years and 27 patients (66\%) were male. Six patients $(14.6 \%)$ had received prior adjuvant chemotherapy (Table 1) and 27 patients (66\%) had serum determination analysis at disease progression. Prior to chemotherapy, the mean serum concentrations of IGF-I and IGFBP-3 were $82.7 \mathrm{ng} / \mathrm{ml}$ (95\%CI, 73.2-92.2) and $2372 \mathrm{ng} / \mathrm{ml}$ (95\%CI, 2121-2623) respectively. We examined the associations of pretreatment serum 
levels of IGF-I and IGFBP-3 with clinical and biological characteristics including age, gender, performance status, LDH, ALP, creatinine, liver involvement, glucose, and the number of organs affected. No statistically significant differences were found between IGF-I and IGFBP-3 and any of the clinical-biological variables studied. MMP-7 was higher in patients with liver involvement (median 7.7, range $3.4-55.8 \mathrm{ng} / \mathrm{ml}$ ) than in those with an unaffected liver (median 5, range $3.4-9.6 \mathrm{ng} / \mathrm{ml} ; P=0.003$ ). MMP-7 was also higher in patients with LDH levels above 450 (median 7.8, range $5.2-42.3 \mathrm{ng} / \mathrm{ml}$ ) than those with lower LDH levels (median 6, range $3.4-55.8 \mathrm{ng} / \mathrm{ml} ; P=0.043$ ).

Table 1 Clinical characteristics of patients at baseline

\begin{tabular}{|c|c|c|}
\hline & $\begin{array}{c}\text { Number of } \\
\text { patients }\end{array}$ & $\%$ \\
\hline \multicolumn{3}{|l|}{ Age, years } \\
\hline Median & 68 & \\
\hline Range & $38-81$ & \\
\hline \multicolumn{3}{|l|}{ Sex } \\
\hline Male & 27 & 65.9 \\
\hline Female & 14 & 34.1 \\
\hline \multicolumn{3}{|c|}{ ECOG performance status } \\
\hline 0 & 19 & 46.3 \\
\hline 1 & 15 & 36.6 \\
\hline 2 & 7 & 17.1 \\
\hline \multicolumn{3}{|c|}{ Number of organs involved } \\
\hline 1 & 28 & 68.3 \\
\hline$>1$ & 13 & 31.7 \\
\hline \multicolumn{3}{|c|}{ Type of organs involved } \\
\hline Liver & 33 & 80.5 \\
\hline Other than liver & 8 & 19.5 \\
\hline \multicolumn{3}{|c|}{ Previous adjuvant chemotherapy } \\
\hline No & 35 & 85.4 \\
\hline Yes & 6 & 14.6 \\
\hline \multicolumn{3}{|l|}{ Serum CEA (ng/ml) } \\
\hline Median & 35 & \\
\hline Range & $1.5-856$ & \\
\hline \multicolumn{3}{|l|}{ Serum LDH (UI/I) } \\
\hline Median & 393.5 & \\
\hline Range & $207-15864$ & \\
\hline \multicolumn{3}{|l|}{ Serum ALP (UI/I) } \\
\hline Median & 319 & \\
\hline Range & $133-1825$ & \\
\hline \multicolumn{3}{|c|}{ Serum basal MMP-7 (ng/ml) } \\
\hline Median & 6.9 & \\
\hline Range & $3.4-55.8$ & \\
\hline \multicolumn{3}{|c|}{ Serum basal IGF (ng/ml) } \\
\hline Mean & 82.7 & \\
\hline Standard deviation & 30 & \\
\hline \multicolumn{3}{|c|}{ Serum basal IGFBP-3 (ng/ml) } \\
\hline Mean & 2372 & \\
\hline Standard deviation & 785.9 & \\
\hline
\end{tabular}

ALP, alkaline phosphatase; CEA, carcinoembrionary antigen; ECOG, Eastern Cooperative Oncology Group; IGF-I, IGF-I; IGFBP-3, IGF-binding protein-3; LDH, lactate dehydrogenase; MMP-7, Matrix metalloproteinase-7.
Analysis of IGF-I and IGFBP-3 levels for each patient showed a persistent and significant correlation before treatment $(r=0.5, P=0.001)$, at 3 months while on chemotherapy $(r=0.44, P=0.004)$, and at disease progression $(r=0.52, P=0.006)$.

Table 2 shows the mean levels of IGF-I, IGFBP-3, and MMP-7 at baseline, before progression and at disease progression. During or after therapy but before disease progression, a significant increase in IGFBP-3 (mean 2527, 95\% CI 2348-2707 ng/ml) was observed, compared with basal levels (mean 2372, 95\% CI $2121-2623 \mathrm{ng} / \mathrm{ml} ; P<0.001$ ). In addition, a significant decrease in IGFBP-3 at disease progression was found (mean $1983 \mathrm{ng} / \mathrm{ml}$ (95\% CI, 1675-2292). Using the IGF-I/IGFBP-3 ratio as a surrogate marker of IGF-I bioavailability, we found a decline in IGF-I/IGFBP-3 ratio during therapy and before progression (mean $0.033,95 \%$ CI 0.030-0.036) compared with basal ratio (mean $0.037,95 \%$ CI $0.033-0.041 ; P<0.001$ ), rising again at progression (mean $0.047,95 \% \mathrm{CI}$ $0.026-0.067 ; P<0.001)$. Figure 1 depicts the changes of these biomarkers taking the baseline levels as the reference.

As shown in Table 2, mean MMP-7 levels increase at disease progression, 14.60 (95\% CI 7.56-21.65) $\mathrm{ng} / \mathrm{ml}$ compared with levels during therapy, 9.57 (95\% CI 6.46-12.69) $\mathrm{ng} / \mathrm{ml}(P=0.001)$. This correlates with decreased IGFBP-3 but not with an increase in IGF-1. Figure 2 plots the relationship between the oscillations observed for MMP-7 and IGFBP-3: the ratio of the level of each marker at progression over the mean of the previous measurements is plotted for each individual. On each axis, lines divide the plot by 1 , distinguishing individuals who elevate the marker at progression (ratio $>1$ ) from those who do not (ratio $\leq 1)$. This figure depicts how IGFBP-3 decreases in most patients with an increase in MMP-7 at progression. Indeed, only one patient appears in the upper right quadrant and most of the patients are in the lower right quadrant.

\section{Discussion}

Our data show how, in previously untreated ACRC patients, IGF-I and IGFBP-3 serum levels oscillate during the evolution of the neoplastic disease. IGFBP-3 increases when the tumor is quiescent or responding to chemotherapy and falls at progression.

To our knowledge, our study is the first to examine the variation over time of IGF-I and IGFBP-3 levels and their association with response to therapy in ACRC. Basal serum levels of IGF-I and IGFBP-3 are in the range of previous studies exploring these 
Table 2 Total plasma insulin-like growth factor-1 (IGF-I), IGFBP-3, IGF-1/IGFBP-3 ratio, and matrix metalloproteinase-7 (MMP-7; mean, $95 \% \mathrm{Cl}$ ) at baseline, before progression, and at progression

\begin{tabular}{llllll}
\hline & $\boldsymbol{n}$ & IGF-I $(\mathrm{ng} / \mathrm{ml})$ & IGFBP-3 $(\mathrm{ng} / \mathrm{ml})$ & IGF-1/IGFBP-3 ratio & MMP-7 (ng/ml) \\
\hline At baseline & 41 & $82.7(73.2-92.2)$ & $2372(2120.7-2623.3)$ & $0.037(0.033-0.041)$ & $10.60(7.21-13.98)$ \\
Before progression $^{\mathrm{a}}$ & 89 & $79.6(73.5-85.7)$ & $2527.2(2347.6-2706.9)^{\dagger}$ & $0.033(0.030-0.036)^{\dagger}$ & $9.57(6.46-12.69)$ \\
At progression $^{27}$ & $71.8(60.6-83)^{\star}$ & $1983.4(1675.2-2291.7)^{\star, \neq}$ & $0.047(0.026-0.067)^{\ddagger}$ & $14.60(7.56-21.65)^{\ddagger}$ \\
\hline
\end{tabular}

IGF-I, IGF-I; IGFBP-3, IGF-binding protein-3; MMP-7, matrix metalloproteinase-7. * $P<0.05$ compared with basal levels (corrected by Bonferroni). ${ }^{\dagger} P<0.001$ compared with basal levels (corrected by Bonferroni). ${ }^{\ddagger} P<0.001$ compared with before progression levels (corrected by Bonferroni).

a'Before progression' values refer to a mean of values obtained every 3 months while undergoing therapy or after therapy but before progression.

biomarkers in a similar patient population (MirakiMoud et al. 2001). Conflicting results have been reported in breast cancer patients treated with adjuvant chemotherapy. Regarding IGF-I, no changes or significant reductions were observed in three small studies with CMF or anthracycline-based schedules (Peyrat et al. 1998, Kajdaniuk \& Marek 2000, Furstenberger et al. 2006). In a larger cohort of patients with breast cancer treated with doseintensified adjuvant anthracycline and taxane therapy, IGF-I and IGFBP-3 levels increased significantly during therapy (Kummel et al. 2007). This last observation is supported by in vitro data showing that genotoxic drugs can increase IGFBP-3 protein levels in tumor cell lines (Zadeh \& Binoux 1997, Grimberg et al. 2005, Patel et al. 2008). As described above, a significant decrease in IGFBP-3 was observed in our study at disease progression, compared with basal and treatment levels. In concordance with our findings, a study of patients diagnosed with advanced breast cancer and undergoing chemotherapy showed a decrease in IGF-I and IGFBP-3 during treatment; only the latter was a predictor of survival, mainly in patients with liver involvement (Holdaway et al. 2003).

A nested case-control study in the Physicians' Health Study (Ma et al. 1999) describes a correlation between IGF-I and IGFBP-3 $(r=0.64)$ in patients diagnosed with colorectal cancer. These results are in line with the steady correlation found between these biomarkers in our study.

In our sample, we also observed that basal levels of serum IGF-I and IGFBP-3 were not associated to any of the biological variables that could affect progression-free survival and overall survival, supporting the idea that IGF-I and IGFBP-3 are probably more influenced by physiologically individual liver synthesis than by colorectal cancer status. In a previously published report, basal plasma levels of IGF-I and IGF-II, but not IGFBP-3, were associated to greater baseline symptomatology in patients with ACRC. By contrast, IGF-I, IGF-II, and IGFBP-3 were not associated to age, performance status, gender, or overall survival (Meyerhardt et al. 2005).

In addition, we found that the decrease in IGFBP-3 at disease progression was associated with increased MMP-7 levels. To our knowledge, increased MMP-7 level has not ever been described at post-chemotherapy disease progression, although increased proteolytic degradation of IGFBP-3 has been described in breast cancer patients (Helle et al. 2001). Furthermore, recent in vitro data have shown that MMP-7 degrades IGFBP2 in colorectal cell lines via proteinase activity (Miyamoto et al. 2007).

The reasons for MMP-7 increases at disease progression after chemotherapy treatment are not well understood. We propose that hypoxia in pretreated tumors could increase over basal status. Under hypoxic conditions, one of the most highly induced genes is
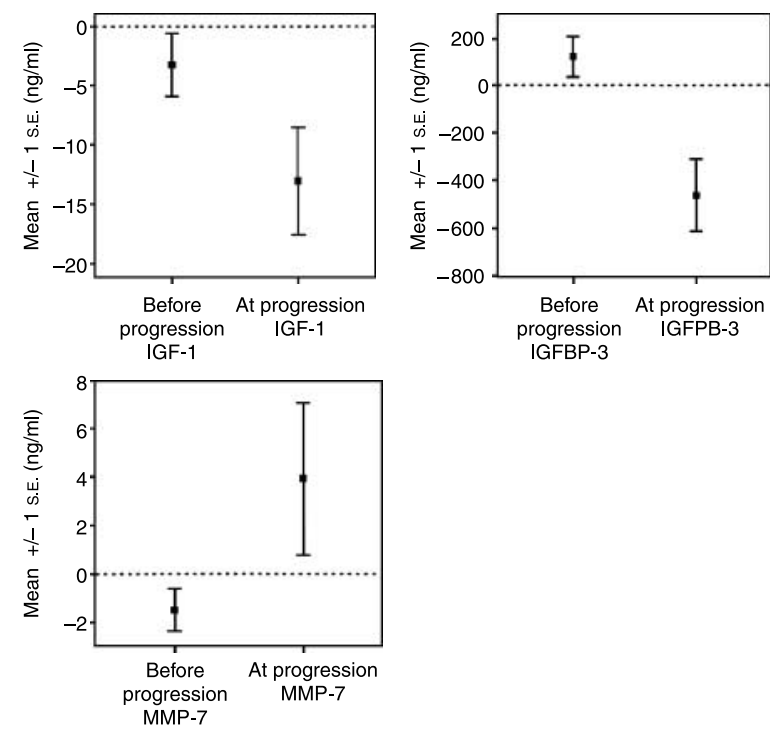

Figure 1 Mean changes to baseline of IGF-1, IGFBP-3, and MMP-7 before progression, and at progressive disease. 


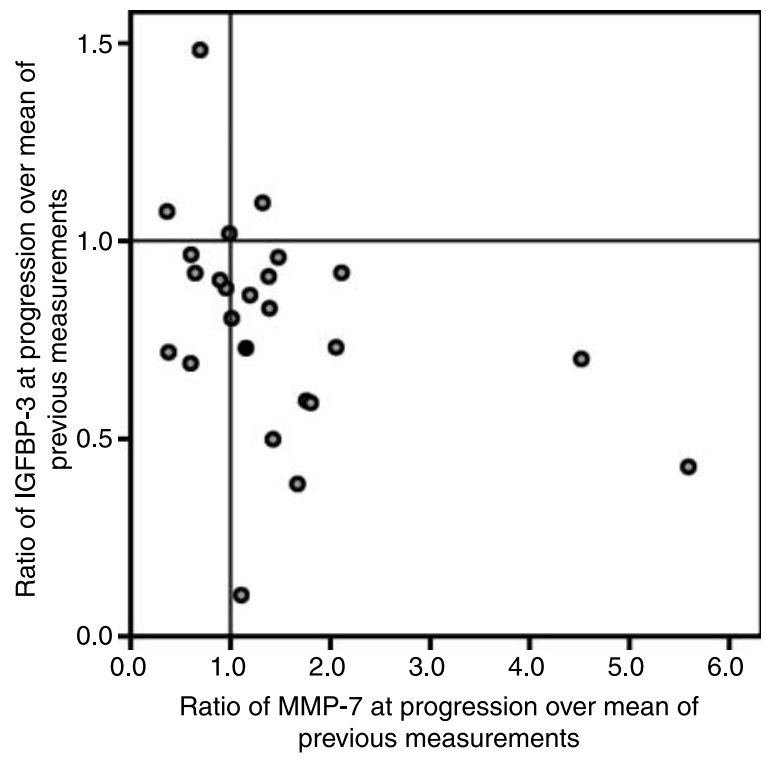

Figure 2 Correlation between levels of IGFBP-3 and MMP-7 before and during therapy compared with that at progressive disease (black dot denotes the overlapping of two individuals). IGFBP-3, IGF-binding protein-3; MMP-7, matrix metalloproteinase-7.

MMP-7 (Burke et al. 2003). Inhibition of MMP-7 prevented ERK1/2 activity and subsequent cell proliferation in response to hypoxia (Sabha et al. 2006). Therefore, we hypothesize that MMP-7 would, under hypoxic conditions, degrade IGFBP-3. As we have not observed increased IGF at disease progression, we cannot rule out decreased levels of IGFBP-3 as contributing to chemotherapy resistance by an IGF-IR-independent pathway. Evidence exists that a fragment of N-terminal (16 KDa) IGFBP-3 has pro-apoptotic activity, mediated through the suppression of the NF-kB survival pathway (Zadeh et al. 2006). It is also known that IGFBP-3 inhibits NF-kB activation in response to TRAIL-induced apoptosis (Williams et al. 2007).

Selection biases are probably irrelevant as long as the sample was collected in a prospective and correlative manner in a prespecified geographic population and time period. This should provide an adequate representation of the area served by the center. Absence of a control group should not be a concern for a descriptive study, as long as the data are analyzed in a paired manner until disease progression. These results, to our knowledge, are the first description of the evolution of these biomarkers during therapy and follow-up in patients with ACRC and allow us to generate the proposed hypothesis about their interaction and role in response to chemotherapy and in cancer progression. Further knowledge and prospective validation of these findings may lead to tools for predicting disease progression and individualizing therapies.

We can conclude that MMP-7 serum levels rise after chemotherapy, degrading IGFBP-3 and decreasing serum levels of this protein. The finding of increased MMP-7 levels at disease progression supports the hypothesis that this protease plays a role in acquired resistance by degrading IGFBP-3.

\section{Declaration of interest}

There is no conflict of interest.

\section{Funding}

Supported by CIBEREHD, Centro de Investigación Biomédica en Red CIBEREHD is funded by the Instituto de Salud Carlos III.

\section{Acknowledgements}

Elaine Lilly, language editing.

\section{References}

Buckbinder L, Talbott R, Velasco-Miguel S, Takenaka I, Faha B, Seizinger BR \& Kley N 1995 Induction of the growth inhibitor IGF-binding protein 3 by p53. Nature 377 646-649.

Burke B, Giannoudis A, Corke KP, Gill D, Wells M, ZieglerHeitbrock L \& Lewis CE 2003 Hypoxia-induced gene expression in human macrophages: implications for ischemic tissues and hypoxia-regulated gene therapy. American Journal of Pathology 163 1233-1243.

Curran S, Dundas SR, Buxton J, Leeman MF, Ramsay R \& Murray GI 2004 Matrix metalloproteinase/tissue inhibitors of matrix metalloproteinase phenotype identifies poor prognosis colorectal cancers. Clinical Cancer Research 10 8229-8234.

Davies M, Gupta S, Goldspink G \& Winslet M 2006 The insulin-like growth factor system and colorectal cancer: clinical and experimental evidence. International Journal of Colorectal Disease 21 201-208.

Furstenberger G, Senn E, Morant R, Bolliger B \& Senn HJ 2006 Serum levels of IGF-1 and IGFBP-3 during adjuvant chemotherapy for primary breast cancer. Breast 15 64-68.

Grimberg, A, Coleman CM, Burns TF, Himelstein BP, Koch CJ, Cohen P \& El-Deiry WS 2005 p53-Dependent and p53-independent induction of insulin-like growth factor binding protein-3 by deoxyribonucleic acid damage and hypoxia. Journal of Clinical Endocrinology and Metabolism 90 3568-3574. 
Helle SI, Geisler S, Aas T, Paulsen T, Holly JM \& Lonning PE 2001 Plasma insulin-like growth factor binding protein-3 proteolysis is increased in primary breast cancer. British Journal of Cancer 85 74-77.

Hemers E, Duval C, McCaig C, Handley M, Dockray GJ \& Varro A 2005 Insulin-like growth factor binding protein-5 is a target of matrix metalloproteinase-7: implications for epithelial-mesenchymal signaling. Cancer Research $\mathbf{6 5}$ 7363-7369.

Holdaway IM, Mason BH, Lethaby AE, Singh V, Harvey VJ, Thompson PI \& Evans BD 2003 Serum insulin-like growth factor-I and insulin-like growth factor binding protein-3 following chemotherapy for advanced breast cancer. Australian and New Zealand Journal of Surgery 73 905-908.

Jenkins PJ, Khalaf S, Ogunkolade W, McCarthy K, David T, Hands RE, Davies D \& Bustin SA 2005 Differential expression of IGF-binding protein-3 in normal and malignant colon and its influence on apoptosis. Endocrine-Related Cancer 12 891-901.

Jones JI \& Clemmons DR 1995 Insulin-like growth factors and their binding proteins: biological actions. Endocrine Reviews 16 3-34.

Kajdaniuk D \& Marek B 2000 Influence of adjuvant chemotherapy with cyclophosphamide, methotrexate and 5-fluorouracil on plasma insulin-like growth factor-I and chosen hormones in breast cancer pre-menopausal patients. Journal of Clinical Pharmacy and Therapeutics 25 67-72.

Kummel S, Eggemann H, Lueftner D, Gebauer N, Buehler H, Schaller G, Schmid P, Kreienberg R, Emons G, Kriner M et al. 2007 Significant changes in circulating plasma levels of IGF1 and IGFBP3 after conventional or doseintensified adjuvant treatment of breast cancer patients with one to three positive lymph nodes. International Journal of Biological Markers 22 186-193.

Kurokawa S, Arimura Y, Yamamoto H, Adachi Y, Endo T, Sato T, Suga T, Hosokawa M, Shinomura Y \& Imai K 2005 Tumour matrilysin expression predicts metastatic potential of stage I (pT1) colon and rectal cancers. Gut 54 1751-1758.

Ma J, Pollak MN, Giovannucci E, Chan JM, Tao Y, Hennekens CH \& Stampfer MJ 1999 Prospective study of colorectal cancer risk in men and plasma levels of insulin-like growth factor (IGF)-I and IGF-binding protein-3. Journal of the National Cancer Institute 91 $620-625$.

Maurel J, Nadal C, Garcia-Albeniz X, Gallego R, Carcereny E, Almendro V, Marmol M, Gallardo E, Maria AJ, Longaron R et al. 2007 Serum matrix metalloproteinase 7 levels identifies poor prognosis advanced colorectal cancer patients. International Journal of Cancer 121 1066-1071.

Meyerhardt JA, Sloan JA, Sargent DJ, Goldberg RM, Pollak M, Morton RF, Ramanathan RK, Williamson SK, Findlay BP \& Fuchs CS 2005 Associations between plasma insulin-like growth factor proteins and C-peptide and quality of life in patients with metastatic colorectal cancer. Cancer Epidemiology, Biomarkers and Prevention 14 1402-1410.

Michell NP, Dent S, Langman MJ \& Eggo MC 1997 Insulinlike growth factor binding proteins as mediators of IGF-I effects on colon cancer cell proliferation. Growth Factors 14 269-277.

Miraki-Moud F, Jenkins PJ, Fairclough PD, Jordan S, Bustin SA, Jones AM, Lowe DG, Monson JP, Grossman AB, Besser GM et al. 2001 Increased levels of insulin-like growth factor binding protein-2 in sera and tumours from patients with colonic neoplasia with and without acromegaly. Clinical Endocrinology 54 499-508.

Miyamoto S, Yano K, Sugimoto S, Ishii G, Hasebe T, Endoh Y, Kodama K, Goya M, Chiba T \& Ochiai A 2004 Matrix metalloproteinase-7 facilitates insulin-like growth factor bioavailability through its proteinase activity on insulinlike growth factor binding protein 3. Cancer Research 64 665-671.

Miyamoto S, Nakamura M, Yano K, Ishii G, Hasebe T, Endoh Y, Sangai T, Maeda H, Shi-Chuang Z, Chiba T et al. 2007 Matrix metalloproteinase-7 triggers the matricrine action of insulin-like growth factor-II via proteinase activity on insulin-like growth factor binding protein 2 in the extracellular matrix. Cancer Science $\mathbf{9 8}$ 685-691.

Nakamura M, Miyamoto S, Maeda H, Ishii G, Hasebe T, Chiba T, Asaka M \& Ochiai A 2005 Matrix metalloproteinase-7 degrades all insulin-like growth factor binding proteins and facilitates insulin-like growth factor bioavailability. Biochemical and Biophysical Research Communications 333 1011-1016.

Patel BB, Sengupta R, Qazi S, Vachhani H, Yu Y, Rishi AK \& Majumdar AP 2008 Curcumin enhances the effects of 5-fluorouracil and oxaliplatin in mediating growth inhibition of colon cancer cells by modulating EGFR and IGF-1R. International Journal of Cancer 122 267-273.

Peyrat JP, Revillion F \& Bonneterre J 1998 Plasma insulinlike growth factor in primary breast cancer patients treated with adjuvant chemotherapy. British Journal of Cancer 77 1669-1671.

Pollak MN, Schernhammer ES \& Hankinson SE 2004 Insulin-like growth factors and neoplasia. Nature Reviews. Cancer 4 505-518.

Pommier G, Garrouste F, el Atiq F, Marvaldi J \& RemacleBonnet M 1993 Potential role of IGFBPS in the regulation of the differentiation state of human colonic carcinoma cells. Growth Regulation 3 80-82.

Sabha N, Aitken K, Lorenzo AJ, Szybowska M, Jairath A \& Bagli DJ 2006 Matrix metalloproteinase-7 and epidermal growth factor receptor mediate hypoxia-induced extracellular signal-regulated kinase $1 / 2$ mitogenactivated protein kinase activation and subsequent proliferation in bladder smooth muscle cells. In Vitro Cellular \& Developmental Biology. Animal 42 124-133. 
Tomii K, Tsukuda K, Toyooka S, Dote H, Hanafusa T, Asano H, Naitou M, Doihara H, Kisimoto T, Katayama H et al. 2007 Aberrant promoter methylation of insulin-like growth factor binding protein-3 gene in human cancers. International Journal of Cancer 120 566-573.

Williams AC, Collard TJ, Perks CM, Newcomb P, Moorghen M, Holly JM \& Paraskeva C 2000 Increased p53-dependent apoptosis by the insulin-like growth factor binding protein IGFBP-3 in human colonic adenoma-derived cells. Cancer Research 60 22-27.

Williams AC, Smartt H, Zadeh AM, Macfarlane M, Paraskeva C \& Collard TJ 2007 Insulin-like growth factor binding protein 3 (IGFBP-3) potentiates TRAIL-induced apoptosis of human colorectal carcinoma cells through inhibition of NF-kappaB. Cell Death and Differentiation 14 137-145.
Zadeh SM \& Binoux M 1997 The 16-kDa proteolytic fragment of insulin-like growth factor (IGF) binding protein-3 inhibits the mitogenic action of fibroblast growth factor on mouse fibroblasts with a targeted disruption of the type 1 IGF receptor gene. Endocrinology 138 3069-3072.

Zadeh AM, Collard TJ, Malik K, Hicks DJ, Paraskeva C \& Williams AC 2006 Induction of apoptosis by the $16-\mathrm{kDa}$ amino-terminal fragment of the insulin-like growth factor binding protein 3 in human colonic carcinoma cells. International Journal of Oncology 29 1279-1286.

Zeng ZS, Shu WP, Cohen AM \& Guillem JG 2002 Matrix metalloproteinase-7 expression in colorectal cancer liver metastases: evidence for involvement of MMP-7 activation in human cancer metastases. Clinical Cancer Research 8 144-148. 